\title{
A Study of Synthesis of Cordierite Powder
}

\author{
Jianwu Cao ${ }^{2, a}$, Xiumei Shi ${ }^{1,2, b}$, Cong Zhang ${ }^{2, \mathrm{c}}$, Zhipeng $\mathrm{Li}^{2, \mathrm{~d}}$, Nengneng Luo ${ }^{2, \mathrm{e}}$, \\ Hong Cui ${ }^{1, f}$ \\ ${ }^{1}$ Northwestern Polytechnical University, Xi'an, 710072, China \\ ${ }^{2}$ Inner Mongolia Metal Material Research Institute, Baotou, 014030, China \\ aylswebken@163.com, bsxm4083@163.com, 'eve8782@163.com, \\ d18753582169@163.com, eluonn1234@163.com, ${ }^{\mathrm{f}}$ cuih1969@163.com
}

Keywords: cordierite powder; solid state reaction

\begin{abstract}
The cordierite powders were successfully synthesized by a solid state reaction method, by using raw materials of high purity powder of $\mathrm{MgO}, \mathrm{Al}_{2} \mathrm{O}_{3}$ and $\mathrm{SiO}_{2}$, mixed according to the stoichiometric ratio of cordierite. The cordierite powders were prepared under different manufacturing conditions and the phase structures were characterized by X-ray diffraction. The results showed the optimizing high purity and better flowability cordierite ceramic powder was achieved by using smaller size oxides particles at calcining temperature of $1425^{\circ} \mathrm{C}$ for 2 hours.
\end{abstract}

\section{Introduction}

Polycrystalline oxide ceramics with cordierite matrix occupies a specific place among the advanced ceramic materials because of its very low (near zero) thermal expansion coefficient, superior thermal shock resistance, excellent chemical resistance and high elastic modulus. Presently, the realisation of the application potential of cordierite matrix ceramics has been the attention of the high stiffness, light weighting and accurateness of cordierite ceramics; it fits well with the designed requirements of equipmental structure, it could be widely used in many fields such as high precision lithography equipment, large space telescope and new optical systems ${ }^{[1-3]}$. But the amount of existing natural cordierite minerals is low, the man made cordierite ceramics were sintered by the cordierite powders which are usually synthesized by natural materials or oxide chemical reagents, to meet the industrial demand. In order to reduce production costs, there are different methods to synthesize for the cordierite powder, using natural material such as talcum, Kaolin, montmorillonite, diatomite, andalusite and sepiolite et al, plus some other industrial solid wastes ${ }^{[4-6]}$. The cordierite powder prepared by the raw material mentioned above could enhance the sintering densification of powder products, but the existing of the second phase which introduced by impurity has some bad influence on thermal expansion coefficient and dielectric properties ${ }^{[7,8]}$. Recently, it has become a research hotspot that how to synthesize the high purity cordierite composite powder and to sinter high density cordierite using the high purity powders in normal atmosphere and lower sintering temperature.

The powders were usually synthesized by precipitate wrapping method, sol-gel method and solid-state reaction method et al. By using precipitate wrapping method the cordierite nano-powders were prepared with highly uniform and fine granularity, but it is such a complicated manufacturing processes of magnesium aluminum hydroxide $\left(\mathrm{MgAl}_{2.6}(\mathrm{OH})_{\mathrm{x}}\right)$ as one of the raw material used in production which had to be prepared by thermal spray method (from spraying melting metal $\mathrm{Mg}, \mathrm{Al}$ within distilled water) ${ }^{[9,10]}$. By using sol-gel method the finer and more uniform cordierite precursor were obtained, but the production process is characterized by complexity, long cycle and high cost which limited the large industrial scale production ${ }^{[11,12]}$. The latest study showed that the high purity cordierite powder with fine particle size and sintering activity could be achieved by solid-state reaction under high temperature using mixed oxides according to the theoretical composition of cordierite, which is the one of the effective methods for large-scale production of high performance cordierite ceramics. Because of the sintering temperature range of cordierite ceramic is very narrow, 
it has several problems such as the non-uniform distribution of cordierite particles size, difficult to control of crystalline growth and introduction of the second phase into the cordierite phase et al., which lead to the big variation of the thermal expansion coefficients of the composite even under very small adjustment of the sintering formula in the process of cordierite ceramic preparation.

In this paper, the cordierite powders were successfully synthesized by a solid state reaction method, by using raw materials of high purity powder of $\mathrm{MgO}, \mathrm{Al}_{2} \mathrm{O}_{3}$ and $\mathrm{SiO}_{2}$, according to the stoichiometric ratio of cordierite. The impact factors such as cordierite particles size, sintering temperature and granulation process for the synthesis cordierite powders were studied by X-ray diffraction.

\section{Experimental procedure}

\section{Materials.}

Highly pure magnesium, aluminum and silicon oxides were employed as raw materials, which were named A and B group with different particle size respectively (see table 1). The experimental formula were designed on the basis of the theoretical composition of cordierite ceramic (the mass fraction of $\mathrm{MgO}, \mathrm{Al}_{2} \mathrm{O}_{3}$ and $\mathrm{SiO}_{2}$ are $14.0 \%, 35.0 \%$ and $51.0 \%$ respectively). Table 1 and table 2 present the raw materials and compositions of studying system.

Table 1 the raw materials used in the experiment

\begin{tabular}{cccccc}
\hline No. & name & $\begin{array}{c}\text { particle size of } \\
\text { A group }\end{array}$ & purity of A group & $\begin{array}{c}\text { particle size } \\
\text { of B group }\end{array}$ & $\begin{array}{c}\text { purity of B } \\
\text { group }\end{array}$ \\
\hline 1 & $\mathrm{MgO}$ & $75 \mu \mathrm{m}$ & $\geqslant 98 \%$ & $1 \mu \mathrm{m}$ & $\geqslant 98.5 \%$ \\
2 & $\mathrm{Al}_{2} \mathrm{O}_{3}$ & $0.5 \mu \mathrm{m}$ & $\geqslant 99.5 \%$ & $0.5 \mu \mathrm{m}$ & $\geqslant 99.9 \%$ \\
3 & $\mathrm{SiO}_{2}$ & $75 \mu \mathrm{m}$ & $\geqslant 98 \%$ & $30 \mathrm{~nm}$ & $\geqslant 99 \%$ \\
\hline
\end{tabular}

Table 2 Formula

\begin{tabular}{cccc}
\hline No. & name & A group & B group \\
\hline 1 & $\mathrm{MgO}$ & $240 \mathrm{~g}$ & $240 \mathrm{~g}$ \\
2 & $\mathrm{Al}_{2} \mathrm{O}_{3}$ & $610 \mathrm{~g}$ & $610 \mathrm{~g}$ \\
3 & $\mathrm{SiO}_{2}$ & $900 \mathrm{~g}$ & $900 \mathrm{~g}$ \\
4 & Absolute Alcohol & $\sim 1000 \mathrm{ml}$ & $\sim 1000 \mathrm{ml}$ \\
\hline
\end{tabular}

\section{Procedure.}

A and B group raw materials from table 2 were ball-milled in acetone with high purity zirconia(99.5\%) grinding media using the absolute alcohol dispersant for about $8 \mathrm{~h}$, subsequent dried and filtered through 60 mesh. Powders milled of A group were synthesized and sintered at different temperature in oxidizing furnace and then held $2 \mathrm{~h}$ at designed temperatures. Powders milled of B group were divided into two parts; one part has the same processing procedure as A group powders; the other part was granulated manually prior to dry pressuring with the pressure of $100 \mathrm{MPa}$ then sintered at different temperature in oxidizing furnace and held $2 \mathrm{~h}$ at designed temperatures, which aimed to compare the effect of synthesizing powders with granulating or without granulating.

Characterization.

X-ray diffraction (XRD) analysis was employed to identify the phases present in the sintered powder. According to theoretical calculation of intensity of main $\mathrm{X}$ ray diffraction lines of cordierite, 
the phases were analysis by the JCPDS database (1996, Sets 1-46)with a search system. The structure was examined with scanning electron microscopy of QUANTA FEG250 made by FEI Corporation.

\section{Results and discussion}

\section{Influence of temperature to the synthesizing cordierite powder.}

The powders milled of A group were sintered at different temperatures and held $2 \mathrm{~h}$ at designed temperatures, the selected temperature were $1380^{\circ} \mathrm{C}, 1390^{\circ} \mathrm{C}, 1400^{\circ} \mathrm{C}, 1410^{\circ} \mathrm{C}, 1420^{\circ} \mathrm{C}, 1430^{\circ} \mathrm{C}$, $1440^{\circ} \mathrm{C}$ and $1450^{\circ} \mathrm{C}$. According to the analysis of the final phases of sintered powders, the best sintering temperature will be determined.

Morphology of cordierite powder after different temperature calcination treatment are given in Fig.1. Fig.1 (a, b, c and d) presents the morphology of the cordierite powder at temperature $1380^{\circ} \mathrm{C}$, $1400^{\circ} \mathrm{C}, 1430^{\circ} \mathrm{C}$ and $1440^{\circ} \mathrm{C}$ respectively. The particles agglomerate slightly and most of them are spherical and fluffy with a small number of reunion at lower sintering temperatures, which is shown in Fig1. (a) and (b). With temperature increasing, reunion agglomeration phenomena raised significantly, as the temperature is above $1430^{\circ} \mathrm{C}$, the morphology of the powder changed from fluffy to solid block with semitransparent, just shown as Fig.1 (c) and (d).
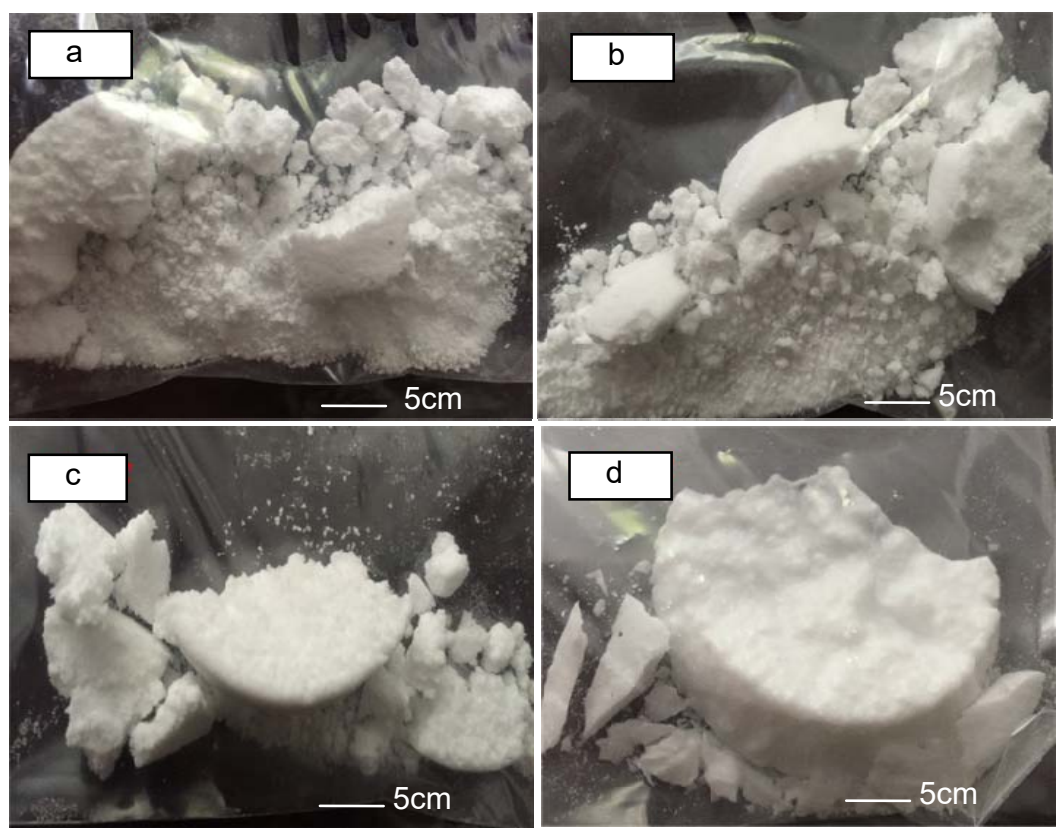

Fig. 1 Photos of as-prepared cordierite powder at various temperatures. (a) $1380^{\circ} \mathrm{C},(\mathrm{b}) 1400^{\circ} \mathrm{C}$, (c) $1430^{\circ} \mathrm{C},(\mathrm{d}) 1440^{\circ} \mathrm{C}$

The XRD patterns of the synthesized cordierite powders at temperature from $1380^{\circ} \mathrm{C}$ to $1450^{\circ} \mathrm{C}$ are shown in Fig.2 (a) and (b). The obvious characteristic peaks of cordierite, magnesium aluminate spinel and silicon dioxide at sintering temperature of $1380^{\circ} \mathrm{C}$ have been identified. In the range of $1390^{\circ} \mathrm{C}$ to $1420^{\circ} \mathrm{C}$, the intensity of peaks of magnesium aluminate spinel and silicon dioxide decreased with temperature increasing, the intensity of peak of cordierite increased that indicated the purity of the cordierite improved. When the sintering temperature reached to $1430^{\circ} \mathrm{C}$, the characteristic peaks of magnesium aluminate spinel and silicon dioxide were disappeared and only cordierite was existed in the synthetic product. On the base of these facts, it was concluded that during the synthesizing process, at first the magnesium aluminate spinel were formed by $\mathrm{MgO}$ and $\mathrm{Al}_{2} \mathrm{O}_{3}$, which reacted with $\mathrm{SiO}_{2}$, leading to the formation of cordierite. Because of the sintering temperature range of cordierite ceramic is very narrow, cordierite is completely decomposed into mullite at the increasing temperature of $1450^{\circ} \mathrm{C}$. 

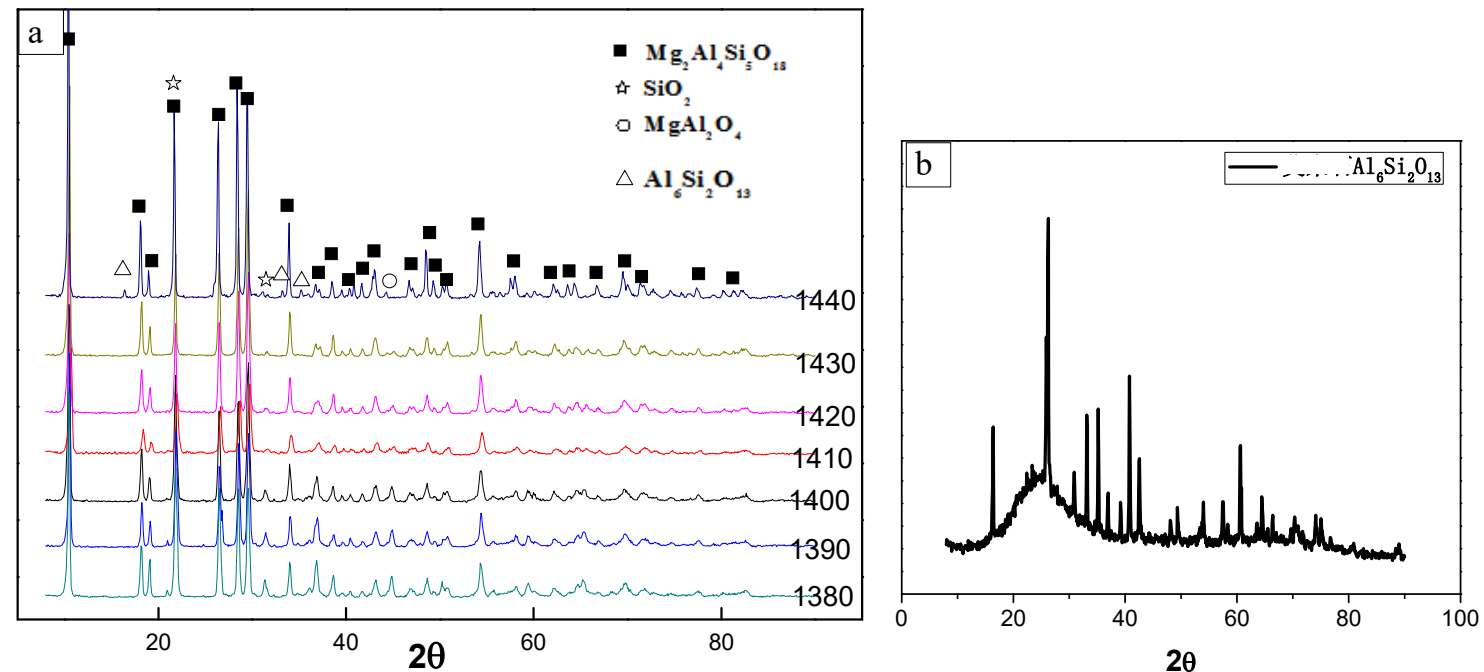

Fig. 2 The XRD patterns of cordierite powders calcined at various temperatures from $1380^{\circ} \mathrm{C}$ to $1450^{\circ} \mathrm{C}$ (a) $1380^{\circ} \mathrm{C} \sim 1440^{\circ} \mathrm{C}$, (b) $1450^{\circ} \mathrm{C}$

\section{Influence of granulation to the synthesizing cordierite powder.}

The powders milled of B group were divided into two parts, one part was just like A group powders which directly sintered at temperature of $1420^{\circ} \mathrm{C}, 1425^{\circ} \mathrm{C}, 1430^{\circ} \mathrm{C}$ and $1450^{\circ} \mathrm{C}$ then held $2 \mathrm{~h}$ at designed temperatures, the other part was granulated manually prior to dry pressuring with the pressure of $100 \mathrm{MPa}$ then sintered at the same selected temperature of $1420^{\circ} \mathrm{C}, 1425^{\circ} \mathrm{C}, 1430^{\circ} \mathrm{C}$ and $1450^{\circ} \mathrm{C}$ then held $2 \mathrm{~h}$. The influence of granulation to the synthesizing cordierite powders is investigated according to the microstructure of the sintered powder.

The powder with granulation or without granulation agglomerate slightly and most of them were white, spherical and fluffy with a small number of reunion at lower sintering temperature. With temperature increasing to $1430^{\circ} \mathrm{C}$, the powder with granulation still remain white, loosely powders with little reunion agglomeration, the powder without granulation shows some white block of reunion agglomerate. As the temperature reached above $1435^{\circ} \mathrm{C}$, the white transparent block were observed in both powders with granulation or without granulation. It implies that granulation could help to reduce the reunion agglomeration of the sintered cordierite powder on the base of obtained facts.

Microstructures of cordierite powders at sintering temperature of $1420^{\circ} \mathrm{C}$ with granulation or without granulation are given in Fig.3. Fig. 3(a) presents the cordierite powder without granulation with irregular polygon, a certain pore size distribution and a wide-range particle size distribution. Fig. 3(b) presents that although the powder with granulation with irregular polygon, but the particles have narrow size distribution and the particle size is much smaller than the powder without granulation.
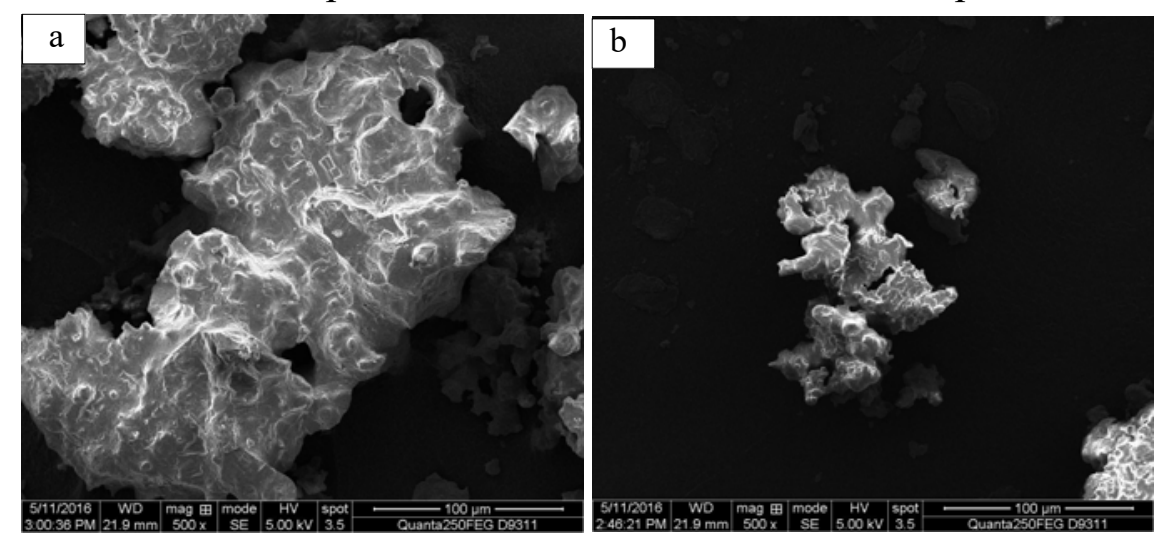

Fig. 3 SEM images of cordierite powder with and non-granulation at $1420^{\circ} \mathrm{C}$

(a) non-granulation (b)granulation

The powders milled of $\mathrm{B}$ group were sintered at different temperatures and held $2 \mathrm{~h}$, the selected temperature points of $1425^{\circ} \mathrm{C}, 1430^{\circ} \mathrm{C}$, and $1435^{\circ} \mathrm{C}$. Microstructures of sintered cordierite powder are 
given in Fig.4. It shows that the growth of the cordierite grains could be enhanced at the three selected temperature point, and the grain microstructure is relatively uniform and dense. By comparison of Fig 4 (a) and (b); the cordierite powder with sintering temperature of $1430^{\circ} \mathrm{C}$ have an ideal grain structure, better edges and corners structure, closely compacted and flake stacking shape. Fig. 4(c) presents that with increasing the temperature, the liquid phase was formed, the grains could generate agglomerations and the grain boundary reduced, amalgamated and disappeared. The results are consistent with the macro-phenomena that the morphology of the powder changed from fluffy to solid block with semitransparent appearance.
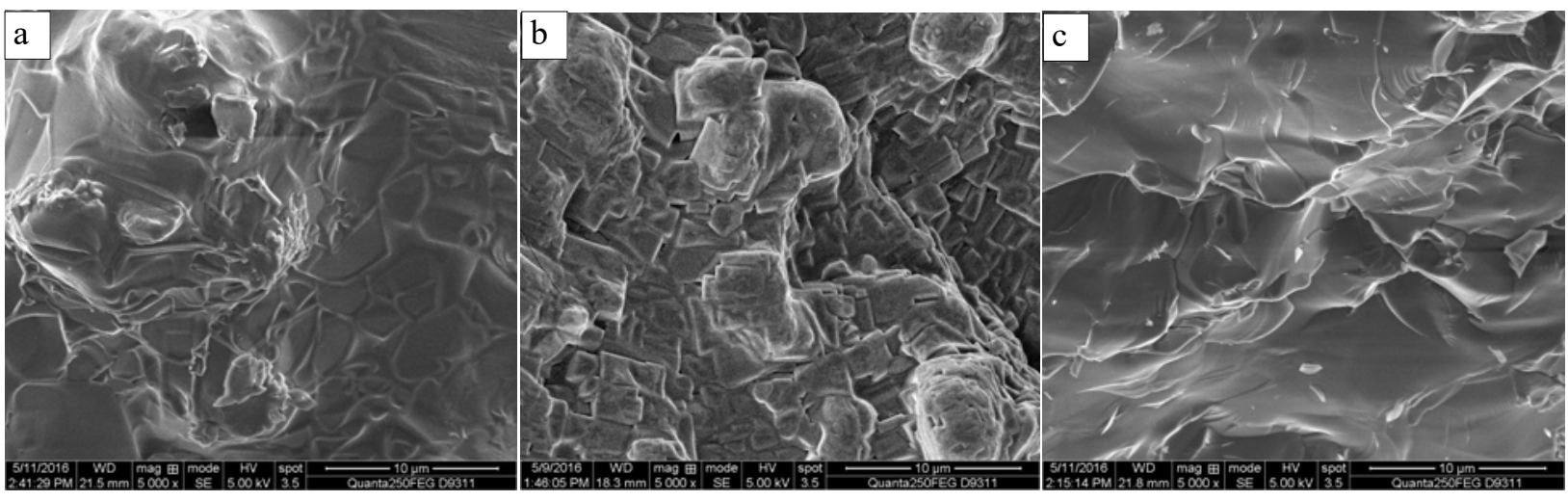

Fig.4 SEM images of cordierite powder with granulation at various temperatures

(a) $1425^{\circ} \mathrm{C},(\mathrm{b}) 1430^{\circ} \mathrm{C}$, (c) $1435^{\circ} \mathrm{C}$

The XRD patterns of the synthesized cordierite powders with B group particles with granulation at temperature of $1435^{\circ} \mathrm{C}$ are shown in Fig.5. The purity of cordierite powder increased with the granulation than those without granulation. This means that the process of granulation could improve the sintering activity and promote the synthesis of cordierite powder. Because of the temperature range for sintering cordierite ceramic is very narrow, cordierite is completely decomposed into mullite phase at the increasing temperature above $1430^{\circ} \mathrm{C}$, which is consistent with the morphology of the powder.

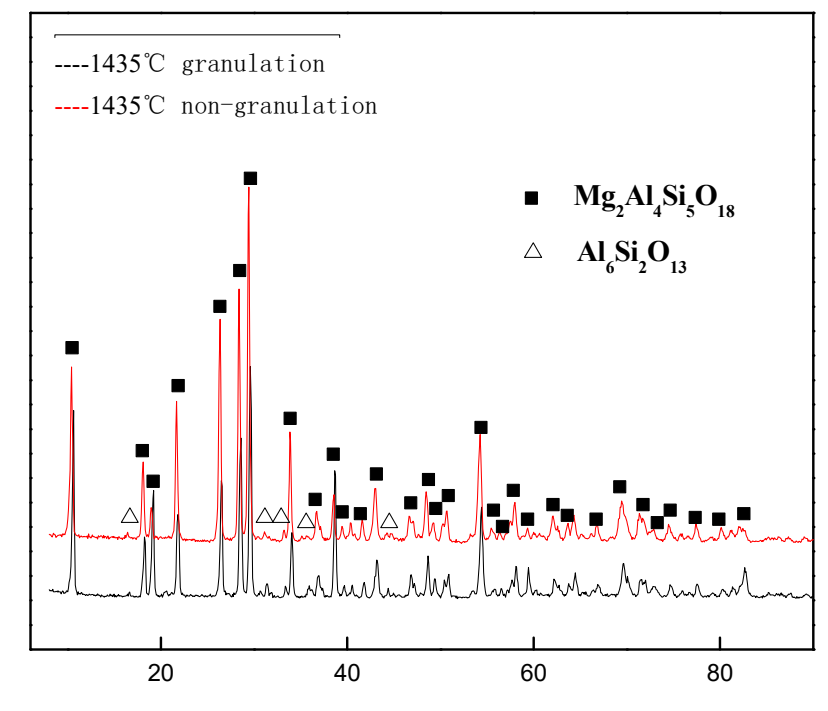

$2 \theta$

Fig.5 The XRD patterns of cordierite powders with granulation and non-granulation calcined at $1435^{\circ} \mathrm{C}$

Influence of particle size to the synthesizing cordierite powder.

The powders milled of B group without granulation were sintered at different temperatures and held $2 \mathrm{~h}$, the selected temperature points of $1420^{\circ} \mathrm{C}, 1425^{\circ} \mathrm{C}$, and $1430^{\circ} \mathrm{C}$. Based on the A group test result of sintered at same selected temperature points (shown in Fig.2), comparing the morphology of the calcined powder, it aimed to investigate the influence of particle size to the synthesizing cordierite powder. 
The XRD patterns of the synthesized cordierite powders with finer raw materials at different temperature are shown in Fig.6. The major phases of $\alpha$-cordierite and $\beta$-cordierite were obtained at the temperature of $1420^{\circ} \mathrm{C}$, impurity phases such as magnesium aluminate spinel and mullite were not precipitated. Comparing the process of sintered cordierite powder with A group coarse raw material, the synthesis temperature decrease and the purity of synthesized powder increase remarkably with B group of fine raw material. The results of cordierite phases precipitating fast and accelerating the phase transformation process with the increasing temperature may be due to the fine particles of smaller particle size and large specific surface area which could improve the sintering activity and decrease the free energy of the system.

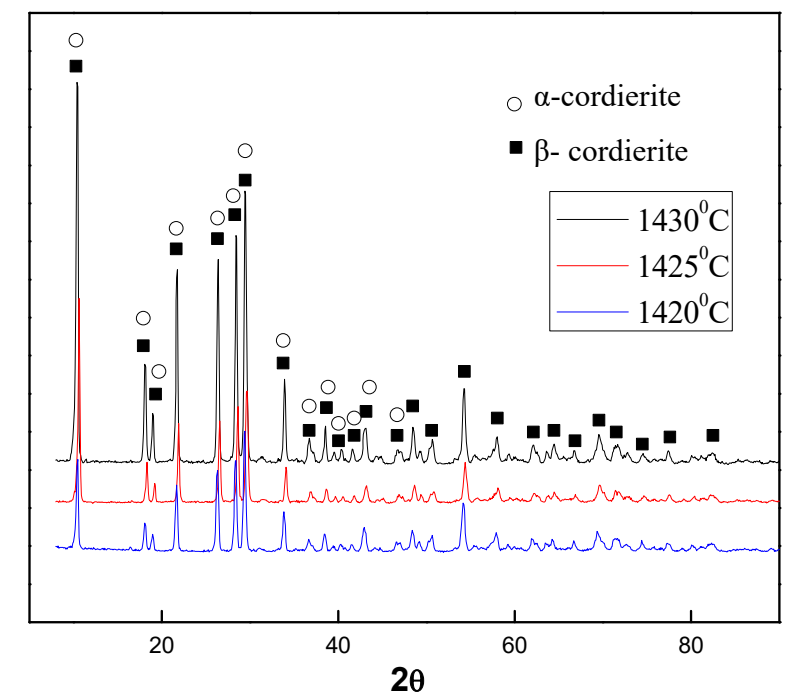

Fig. 6 The XRD patterns of cordierite powders with smaller size oxides particles from $1420^{\circ} \mathrm{C}$ to $1430^{\circ} \mathrm{C}$

Because of its very low coefficient of thermal expansion, excellent dielectric properties and super strength, cordierite material has gained a significant attention in the development of large scale integrated circuit, micro-electronics, aerospace and other fields. The high quality of cordierite powders is one of the key factors for preparing the low expansion ceramics with ideal properties. Synthesizing cordierite powders with solid state reaction has the characteristics of simple operation, better reliability, easy to acquire powders with high purity and uniformed particle size, which has a good role in promoting synthesizing low thermal expansion cordierite ceramics.

\section{Conclusion}

1. The cordierite powder are synthesized by using raw materials with different particle sizes. The results show that under $1430^{\circ} \mathrm{C}$, the purity of cordierite powder increases with the raising sintering temperature, the cordierite phases turn into mullite phases when the sintering temperature above $1430^{\circ} \mathrm{C}$. So the optimum sintering temperature is not beyond $1430^{\circ} \mathrm{C}$.

2. The study of influence of granulation to the synthesizing cordierite powder indicates that granulation is beneficial to reducing the block phenomena of calcined powder.

3. The study of influence of particle size to the synthesizing cordierite powder shows that the synthesis temperature decrease and the purity of synthesized powder increase remarkably with fine raw materials. 


\section{Acknowledgments}

This work was supported by the National Basic Research Program of China(973 Program) No.2014CB660812 and by the natural Science Foundation of Ningbo Science and Technology Department, 201401A6105058.

\section{References}

[1] Xiaoqi Wang, Kun Zhou, Xiaodong Chu et al: Synthesis and Infrared Radiation Properties of Cordierite-Zirconia Composite Powders, J. China powder science and technology,2012, Vol.18 No.(4): $1-5$

[2] Crosjean P: Cordierite ceramics, Inter. ceram, 1993, 42(1):11-15

[3] GÜNAYE: Sintering behavior and properties of sepiolite-based cordierite compositions with added boron oxide, J.Turkish J Eng Env Sci, 2011, 35(2): 83-92

[4] D. Pal, A. K. Chakraborty, Suchitra Sen: The synthesis, characterization and sintering of sol-gel derived cordierite ceramics for electronic applications, J. Mater. Sci, 1996, 31: 3995-4005

[5] M. F. Hochella Akira Miyakew: Effects of Ionic Size in the Tetrahedral and Octahedral Sites on the Thermal Expansion of Low-Temperature Cordierite,J. Am. Ceram..2005.22(2):362-366

[6] Douy A, et al: Spray-dried homogeneous cordierite and MLAS glass ceramic powders, J. Eur. Ceram. Soc, 1992, 9: 373-380

[7] Gonzalez-Velasco J R, Gutierrez-Ortiz M A, Ferret R, et al.: Synthesis of cordierite monolithic honeycomb by solid state reaction of precursor oxides, J.Mster.Sci, 1999, 34(9): 1999-2002

[8] Emre Yalamac, Sedat Akkurt: Additive and intensive grinding effects on the synthesis of cordierite J. Ceram Int., 2006, 32(7): 825-832

[9] Rodrigues Neto, Joao B, Moreno Rodrigo. Effect of mechanical activation on the theology and casting performance of kaolin/talc/alumina suspensions for manufacturing dense cordierite bodies,J. Appl. Clay Sci.,2008,38(12):209-218

[10] Cristina Ghitulica, Ecaterina ronescu, Oana Nicola, et a1.: Preparation and characterization of cordierite powders. J. Eur Ceram Soc., 2007,27(5):711-713

[11] Ying Cao, Wanzhong Ying, Guosheng Wang et al.: Preparation of Cordierite Nano-particles by Sol-Gel Process and Characterization, J.China powder science and technology,2012,Vol.18 No.(4):24-29

[12] Ismail MGMU, T sunatori H, Nakai Z.: Preparation ofmullite cordiefite composite powders by the sol-gel method:its characteristics and sintering.J. Am. Ceram. Soc., 1990,73(3):537-543 